\title{
Muito além da sala de aula: letramento crítico e ensino de língua inglesa
}

\section{William Mineo Tagata}

Professor Doutor do Instituto de Letras e Linguística da UFU - Universidade Federal de Uberlândia; Programa de Pós-Graduação em Estudos Linguísticos (PPGEL); Uberlândia; Minas Gerais; Brasil. email: wtagata@gmail.com

Resumo: Este artigo se propõe a refletir sobre a importância do letramento crítico para 0 ensino de língua inglesa. De acordo com o letramento crítico, o ensino da língua estrangeira pode favorecer o desenvolvimento de uma consciência crítica acerca de como nossos sentidos e identidades são construídos, além de apontar para a necessidade de repensarmos os conhecimentos pertinentes à formação de professores. Apresentamos ainda o depoimento de uma professora de inglês, participante de um programa de formação de professores, que ilustra as possibilidades de reconfiguração epistemológica desencadeada pelo processo de formação continuada segundo o letramento crítico, sobretudo no que diz respeito ao exercício de uma agência por parte de professores e alunos.

Palavras-chave: letramento crítico; ensino de língua inglesa; agência
Abstract: This paper sets out to reflect on the importance of critical literacy to English language teaching. According to critical literacy, teaching a foreign language can favor the development of a critical awareness of how meanings and identities are constructed, as well as suggesting the need to rethink the knowledge base in teacher education programmes. We also present excerpts from an interview with an English teacher, participant in a teacher development programme, which illustrate the possibilities of an epistemological reconceptualization that teacher development programmes informed by critical literacies can bring about, especially as concerns the exercise of agency on the teachers' and students' part.

Keywords: critical literacy; English language teaching; agency 



\section{Introdução}

"Muito além do jardim", filme dirigido por Hal Ashby em 1979, traz Peter Sellers no papel de Chance, um jardineiro que, após a morte do patrão, perambula pelas ruas de Washington até ser atropelado por uma limusine, pertencente à mulher de um empresário bem sucedido (papel de Shirley MacLaine). Pouco acostumado à vida fora da casa do ex-patrão, o jardineiro raramente saía de seu aposento na mansão onde vivia, tendo como única companhia a TV sempre ligada - sua única fonte de entretenimento, informação e conhecimento. Apesar de pouco instruído, Chance - nome bastante apropriado para o personagem de Sellers ${ }^{1}$ - ganha a confiança de seu anfitrião, impressionado com a sabedoria do jardineiro, feita de frases feitas e comentários clichês que parecem ter saído de propagandas e programas de TV. Com a ajuda de seu anfitrião, Chance acaba conhecendo figuras importantes e politicamente influentes, a quem logo conquista com seu "conhecimento".

O filme de Ashby permanece atual porque ainda estamos em uma sociedade fascinada pela televisão, cujas imagens ubíquas informam, entretêm, instruem, constituem e povoam nossas conversas mais corriqueiras. Além disso, o filme me parece oportuno para introduzir algumas das questões que vem norteando minhas reflexões como pesquisador, e que abordo neste texto: o que conta como conhecimento em nossa sociedade, e o que não conta? Para quem, e por quê? Que tipo de conjuntura favorece a hegemonia de alguns saberes e conhecimentos? $\mathrm{O}$ que leva alguém a ser visto como culto? Ou letrado? $\mathrm{O}$ que é letramento, e a que interesses serve? Como as novas tecnologias digitais mudam a forma como construímos, valorizamos e nos relacionamos com o conhecimento? De que maneiras os professores de inglês têm utilizado essas tecnologias dentro e fora da sala de aula? Como e por que devemos problematizar essas questões em programas de
1 "chance", em inglês, significa "chance", "oportunidade". Mas também quer dizer “acidental”, "ao acaso". 
formação inicial e continuada de professores? Como criar oportunidades para a emergência e o desenvolvimento de uma consciência crítica nesses programas? Como se pode entender letramento crítico, e qual sua importância na formação de professores, alunos, e cidadãos?

Não há, obviamente, espaço aqui para tratar de todas essas questões complexas com a devida profundidade que tal reflexão merece. Mas neste texto me aventuro a abordar algumas delas, especialmente aquelas diretamente relacionadas à minha pesquisa com um grupo de professores de inglês da rede municipal da cidade de Uberlândia, Minas Gerais, com quem venho trabalhando desde 2012. Mais adiante será possível perceber como essas questões também interessam a esses professores, cujos depoimentos tive a oportunidade de entrevistar; selecionei trechos desses depoimentos para tecer reflexões sobre a importância do letramento crítico na formação de professores de língua inglesa e seus alunos.

\section{Que conhecimentos devem fazer parte da formação dos professores de línguas?}

Um artigo de Freeman e Johnson (1998), publicado em um volume do periódico TESOL Quarterly dedicado ao tema da formação de professores, já defendia a necessidade de repensar a formação de professores de línguas. Em busca de alternativas a uma formação mais tradicional, baseada em teorias e métodos gerais sobre como ensinar uma língua eficientemente, aplicáveis a qualquer contexto de aprendizado, os autores apontam pesquisas feitas a partir da década de 80 , sobre como os professores concebem suas próprias crenças, conhecimentos e práticas em sala de aula. Segundo os autores, as pesquisas sugerem que esses conhecimentos e crenças sobre o papel do professor, o conteúdo a ser lecionado, o papel dos alunos e da sala 
de aula, são construídos a partir de suas experiências de vida e de sua escolarização. Portanto, a formação dos professores é socialmente constituída e negociada, uma vez que seu conhecimento se constrói na interação com alunos, pais e outros envolvidos no processo educacional, como colegas de trabalho, coordenadores, diretores e administradores escolares. Assim, como alternativa aos programas tradicionais de formação de professores de línguas, apoiados na transmissão de teorias e métodos universais, Freeman e Johnson sugerem a implementação de programas elaborados a partir das seguintes questões: quem ensina o quê para quem, e onde? (FREEMAN \& JOHNSON, 1998, p.405).

Ao defender a realização de programas de formação de professores em torno de questões aparentemente tão simples, os autores ressaltam a importância de levarmos em conta os contextos dos processos de ensino e aprendizagem de línguas - tanto o contexto imediato da sala de aula quanto o contexto sociocultural mais amplo onde ocorrem esses processos - de forma que as decisões e escolhas sobre quais métodos adotar, quais conteúdos ensinar, e a partir de quais justificativas teóricoepistemológicas, sejam compreendidas "contra o pano de fundo das vidas profissionais dos professores, dentro dos ambientes onde trabalham, e nas circunstâncias desse trabalho" (FREEMAN \& JOHNSON, 1998, p.405, minha tradução). ${ }^{2}$ Além disso, os autores enfatizam a interdependência entre os diferentes fatores que influenciam diretamente o trabalho do professor, desde a localização espacial e a infraestrutura da sala de aula, até a existência ou não de políticas linguísticas específicas. É nesse "terreno social" em que decisões relativas ao planejamento, implementação e avaliação do ensino de língua são tomadas, cabendo ao professor aprender a negociar com os diferentes fatores e personagens em jogo na sala de aula e fora dela:
${ }^{2}$ No original, "against the backdrop of teachers' professional lives, within the settings where they work, and within the circumstances of that work". 
Estudar, compreender e aprender como negociar a dinâmica desses ambientes poderosos, em que algumas ações e modos de ser são valorizados e encorajados, enquanto outros são reprimidos, ignorados e até silenciados, são cruciais na construção da formação efetiva de professores (FREEMAN \& JOHNSON, 1998, p. 409, minha tradução). ${ }^{3}$

Freeman e Johnson (1998) falam da necessidade do professor estudar, compreender e aprender a dinâmica do ambiente educacional, destacando, assim, o papel do professor enquanto aprendiz de sua própria

${ }^{3}$ No original, "studying, understanding and learning how to negotiate the dynamics of these powerful environments, in which some actions and ways of being are valued and encouraged whereas others are downplayed, ignored, and even silenced, is critical to constructing effective teacher education". prática. Esse processo de aprendizado certamente envolve não só a conscientização da influência dos contextos sociocultural e institucional sobre suas ações na sala de aula (encorajando determinadas práticas pedagógicas e desestimulando e até silenciando outras), mas também a conscientização do impacto de suas escolhas e ações para os alunos, a escola e a comunidade. É nesse sentido que os autores destacam o caráter político do fazer pedagógico, necessariamente situado e comprometido com uma conjuntura social, cultural e institucional em relação à qual os professores precisam se posicionar criticamente:

Acreditamos que os professores devem compreender suas próprias crenças e conhecimentos sobre aprendizado e ensino e estar plenamente conscientes do impacto certo desses conhecimentos e crenças em suas salas de aula e aprendizes de línguas dentro delas. Acreditamos que os professores devem estar plenamente conscientes e desenvolver uma postura questionadora em relação às complexas estruturas sociais, culturais e institucionais que atravessam os cenários profissionais onde trabalham. E acreditamos que os professores devem ser capazes de articular, para si mesmos e para os outros, os processos extremamente situados e interpretativos envolvidos no aprendizado e no ensino enquanto ocorrem 
nos próprios contextos institucionais dos professores. ${ }^{4}$ (FREEMAN \& JOHNSON, 1998, p.412, minha tradução)

Por que ensinar determinados conteúdos ou habilidades e não outros? Por que (não) traduzir de uma língua para outra? Por que optar por um ensino limitado a aspectos linguístico-gramaticais? Por que utilizar determinado texto em vez de outro? E quais as consequências dessas escolhas, no âmbito da sala de aula e para além dela? Certa vez Renata ${ }^{5}$, uma professora de inglês em formação inicial, orientada por uma colega da instituição em que trabalho, sentiu-se incomodada com as imagens clichê de cidades turísticas localizadas na Europa, tema da unidade do livro didático que deveria lecionar em breve. Com o aval da orientadora, preparou uma apresentação em Powerpoint com imagens que julgava serem menos estereotipadas, e que talvez pudessem estimular um debate interessante com os alunos. Assim, em vez da foto da Torre Eiffel rodeada por turistas com câmeras em punho, presente no livro didático, a professora optou por mostrar em seu Powerpoint um grupo de mulheres transeuntes vestindo burkas, tendo a Torre como pano de fundo. Ao comentar o uso desse material com a orientadora, a professora relatou ter havido surpresa por parte de alguns alunos, que desconheciam o caráter multiétnico da sociedade francesa. Nesse sentido, podese dizer que tanto Renata quanto seus alunos tiveram uma experiência de letramento crítico que suscitou uma discussão sobre a formação multirracial nos países europeus, e a convivência - nem sempre pacífica - entre diferentes etnias, culturas e religiões em um mesmo país.

\section{0 letramento crítico na aula de inglês}

Até a década de 80 , o conceito de letramento estava inextricavelmente relacionado ao domínio da escrita. Ser letrado, nessa perspectiva, compreendia ser
${ }^{4}$ No original, "we believe that teachers must understand their own beliefs and knowledge about learning and teaching and be thoroughly aware of the certain impact of such knowledge and beliefs on their classrooms and the language learners in them. We believe that teachers must be fully aware and develop a questioning stance toward the complex social, cultural and institutional structures that pervade the professional landscapes where they work. And we believe that teachers must be able to articulate, to themselves and to others, the highly situated and interpretative processes involved in both language teaching and language learning as they occur in the teachers' own institutional contexts".

${ }^{5}$ Os nomes aqui mencionados são fictícios. 
capaz de codificar e decodificar a linguagem escrita, cujo aprendizado era tido como condição para o progresso social e econômico - daí a criação de programas de alfabetização de jovens e adultos em comunidades e países com altos índices de analfabetismo. A ideia de que o conhecimento da escrita seria capaz de promover avanços sociais, independentemente do contexto em que tais programas de alfabetização seriam implantados, passou a ser questionada por estudiosos de letramento menos interessados na escrita enquanto simples tecnologia, e mais preocupados com os aspectos ideológicos de sua aquisição, e seus efeitos em contextos sociais específicos (STREET, 1984). A partir de então, os estudos passaram a rejeitar a concepção de letramento enquanto mera aquisição de conhecimentos ou habilidades universais, relacionados à capacidade de codificar e decodificar a linguagem escrita, propondo, em vez disso, uma reflexão sobre os diferentes modos como construímos sentidos - não apenas através da escrita, mas também do gesto, da imagem, do som, do espaço, entre outros. Por isso, estudiosos como Street (1984) passaram a investigar as formas pelas quais podemos nos apropriar e transformar esses sentidos, abrindo caminho para mudanças pessoais e sociais profundas, naquilo que se convencionou chamar de letramento crítico.

Segundo Cope \& Kalantzis (2012), os letramentos críticos procuram valorizar as vozes e experiências que professores, alunos e professores-alunos trazem para a escola, valorizando-os enquanto cidadãos responsáveis por seu processo de aprendizagem e agentes capazes de mudança. Nessa perspectiva crítica, os diversos tipos de letramentos - alfabético, visual, digital, espacial, entre outros - são uma ferramenta para ajudar os alunos a compreenderem e apropriar-se das formas em que os significados são construídos em suas vidas, ao invés de se sentirem alienados, desrespeitados ou excluídos por textos 
desconhecidos. Por isso, o letramento não pode mais ser visto apenas enquanto uma aquisição de conhecimentos ou habilidades técnicas, como simples capacidade de codificar e decodificar a linguagem escrita. Para Cope \& Kalantzis (2012), o letramento envolve a compreensão de como construímos sentidos, como esses sentidos nos posicionam de formas específicas no mundo, e como podemos nos apropriar e transformar esses sentidos, destarte criando condições favoráveis para mudanças pessoais e sociais. De acordo com esses autores,

O objetivo dos letramentos críticos é ajudar os aprendizes a compreenderem as formas pelas quais as coisas são construídas no mundo pelas ações e valores das pessoas. Seu pressuposto é que o mundo do aprendizado não é simplesmente uma série de regras a serem obedecidas, fatos a serem aprendidos e autoridades do conhecimento a serem seguidas. Em termos textuais, uma pessoa criticamente letrada identifica tópicos relevantes e poderosos, analisa e registra evidências, considera pontos de vista alternativos, formula possíveis soluções para os problemas e talvez também teste essas soluções, chegue a suas próprias conclusões e construa argumentos bem elaborados para defender suas posições". ${ }^{6}$ (COPE \& KALANTZIS, 2012, p.149, minha tradução)

Mais do que apenas ensinar regras gramaticais, o professor de inglês deveria, numa perspectiva de letramento crítico, levar os alunos a refletir sobre o status dessas regras, e como os usuários da língua inglesa se relacionam com elas, respeitando-as ou modificandoas conforme seus próprios interesses, necessidades ou intenções comunicativas em uma situação determinada. Por exemplo, essas regras se aplicam igualmente ao inglês falado e ao escrito? Admitem variações e exceções? São conhecidas, validadas e utilizadas por quais classes sociais, faixas etárias, grupos étnico-raciais, e em quais situações? Quais as implicações e consequências de aderir a elas ou
${ }^{6}$ No original, "the aim of critical literacies is to help learners understand the ways things are constructed in the world by people's values and actions. Its assumption is that the world of learning is not simply a series of rules to be obeyed, facts to be learned and knowledge authorities to be followed. In textual terms, a critically literate person identifies relevant and powerful topics, analyses and documents evidence, considers alternative points of view, formulates possible solutions to problems and perhaps also tries these solutions, comes to their own conclusions and makes wellreasoned arguments to support their case". 
não, por exemplo, no tocante ao modo como utilizamos a língua para constituirmos eafirmarmos nossas identidades? Nessa perspectiva de letramento crítico, o professor de inglês que opta por ensinar o verbo to be para seus alunos pode muito bem trazer à baila casos como "Bess, you is my woman now", do musical "Porgy and Bess", dos irmãos Gershwin, e discutir o contexto sociocultural de uso desse tipo de linguagem. Ou então mencionar formas como ain't, praticamente ignorada pelos livros didáticos tradicionais, porém amplamente utilizada em determinados contextos. Ou ainda problematizar outros desvios da norma, como no verso "she don't lie", escrito por Eric Clapton.

Para Cope e Kalantzis (2012), práticas de letramento crítico devem, sobretudo, promover valores democráticos, de modo que os interesses, expectativas, crenças e valores dos alunos sejam o mote da aula de línguas, idealmente menos centrada em conteúdos ou habilidades desvinculados de seu contexto de uso, e mais preocupadas com questões pertinentes à realidade social do aluno. Um exemplo de prática de letramento crítico particularmente bem sucedido, mencionado pelos autores (2012), diz respeito ao uso de música rap por dois professores de inglês em uma escola pública nos Estados Unidos. Diante da resistência de seus alunos ao estudo de textos literários canônicos, esses professores passaram a utilizar letras de música rappara ensinar língua e literatura inglesa, de forma a valorizar as formas de cultura popular com os quais seus alunos estavam mais familiarizados. Desse modo, os professores puderam desenvolver um currículo a partir de materiais relevantes para seus alunos, levando em consideração suas identidades e experiências pessoais. Um currículo assim deve ser flexível a ponto de dar conta de interesses e histórias de vida diferentes, e também a ponto de possibilitar a emergência de uma nova configuração epistemológica, na qual o conhecimento 
não consiste apenas de um conjunto de fatos ou verdades fixas e imutáveis. No caso da língua inglesa, os alunos ainda devem aprender o conjunto de regras gramaticais - cujo conhecimento é, sem dúvida, importante para a comunicação bem sucedida -, mas também precisam saber que essas regras descrevem a língua como um sistema abstrato, descontextualizado, e que em diferentes situações de uso, por falantes situados em diversos contextos socioculturais, podem não ser aplicáveis. Além disso, a língua está em constante evolução - tema de inúmeras pesquisas em linguística, porém pouco lembrado em aulas de língua inglesa. ${ }^{7}$ Por isso, conforme sugerem Cope e Kalantzis (2012), o conhecimento é muito mais uma questão de perspectiva - neste caso, a perspectiva de quem usa a língua, em qual contexto e em qual época, e com quais propósitos - do que um conjunto de fatos.

\section{Além da sala de aula de língua inglesa: 0 caso de Tereza}

No ano de 2012, tive a oportunidade de conviver com professores da rede municipal da cidade de Uberlândia (MG), participantes de um curso de formação continuada oferecido como parte de um projeto de extensão do Instituto de Letras da Universidade Federal de Uberlândia, onde leciono. Após os encontros quinzenais, voltados ao aperfeiçoamento de conhecimentos de língua e cultura dos países de língua inglesa, entrevistei dez professores com diferentes experiências profissionais. As entrevistas foram realizadas apenas com o intuito de avaliar a contribuição do curso para a formação desses professores, e foram gravadas em áudio e posteriormente transcritas por mim. Através delas, foi possível descobrir que alguns professores cumpriam dupla jornada de trabalho, na rede municipal e na rede estadual, e outros trabalhavam na rede pública e também em escolas de línguas; alguns estavam na rede pública há menos de dois anos, outros possuíam
${ }^{7}$ Jenkins (2000), em seu estudo sobre o inglês como língua internacional, se arrisca a dizer que, com a disseminação da língua inglesa e um número cada vez maior de falantes não-nativos do que nativos, certos fonemas como / $\theta /$, tendem a desaparecer. Em outro nível, o morfológico, por exemplo, a autora prevê que substantivos incontáveis como "information", passem a ter a flexão de plural, dado o grande número de falantes não-nativos da língua que fazem a flexão indevida. 
ampla experiência profissional; alguns trabalhavam em bairros periféricos da cidade, outros em escolas situadas na zona rural. Apesar das diferenças, todos foram unânimes em reconhecer a importância dos novos letramentos e possibilidades para o ensino e aprendizado de línguas. Também foram unânimes em apontar dificuldades para a utilização de recursos tecnológicos em sala da aula, como por exemplo, número insuficiente de equipamentos, falta de destreza na utilização desses equipamentos e ausência de suporte tecnológico. Essas dificuldades foram mencionadas por boa parte dos professores, entre os quais a professora Tereza, que relatou ter levado seu próprio notebook para a escola duas ou três vezes, para realizar atividades para estimular o aprendizado da língua inglesa através da música e do teatro, apesar da falta de infraestrutura adequada:

Eu estava com o planejamento de fazer pequenas histórias que não durassem mais de quinze, vinte minutos para trabalhar com eles o inglês, fazer, tenho alguns amigos meus que mexem com teatro, a gente montar, escrever algumas peças, para a gente montar, filmar e trabalhar, para eu trabalhar com os meninos, pegar temas que eles já têm, porque a maioria dos filmes não dá pra eu trabalhar, e eu, não tem essa disponibilidade da escola em fornecer esse espaço.

Em seguida, perguntei-lhe porque achava importante trabalhar com essas pequenas histórias, a partir de temas "que eles já têm":

Eu vejo como uma coisa muito boa, porque elas podem ser adaptadas exatamente para a necessidade daquele grupo de alunos que você está imediatamente, então você responde uma necessidade praticamente imediata dos alunos com os quais você está lidando, então eu vejo uma necessidade deles. Por exemplo, eles não gostam de trabalhar em casa, e esse é um problema que os pais deles às vezes chegam na escola reclamando. 
Então eu posso fazer uma esquete sobre essa questão do trabalho, do trabalho infantil, até que ponto ele é considerado escravo e indesejado, ou até que ponto ele é considerado uma coisa boa para a formação dessa criança como cidadão, posso escrever uma esquete, fazer uma peça e a gente pode representar ela e filmar ela, e tratar desse assunto. Então eu vi essa perspectiva, e uma outra perspectiva que eu tô amadurecendo, só que eu não tenho conhecimento de informática suficiente, era para fazer jogos com isso, porque essas esquetes, a intenção era fazer elas em forma de mímica e fazer como se fosse um joguinho de computador com ela para adaptar e fazer; se eles quisessem ouvir em inglês aquilo que estava sendo executada, eles passavam por uma etapa de questões relacionadas ao vocabulário que está sendo abordado na esquete, e aí, se eles acertassem eles teriam a opção de colocar em português ou inglês a sonorização daquela esquete, então era como se fosse um joguinho mesmo.

Partir do que "eles já têm”, para a Tereza, significa trazer para a sala de aula questões presentes na vida deles, como o trabalho infantil e cidadania, temas que nortearão a elaboração de esquetes a serem usados para o ensino de língua inglesa. Podemos perceber aí a preocupação da professora em propiciar uma aprendizagem situada (GEE, 2004), contextualizada, relativa e relevante aos contextos das experiências vividas por seus alunos. Outra ideia interessante mencionada pela Tereza é o desejo de transformar os esquetes em jogos de computador em que os jogadores teriam o acesso ao áudio gravado na língua que escolhessem, "como se fosse um joguinho mesmo". Para isso, teriam que passar por uma série de etapas com questões relacionadas ao vocabulário estudado. Aqui, Tereza revela a crença no potencial dos jogos de computador para o aprendizado, enumerando algumas das características que Gee (2004) aponta. Primeiro, a questão da multimodalidade dos jogos, apoiada em 
diversos tipos de linguagem - escrita, visual, gestual (mímica) e sonora, entre outras - que se complementam e se reforçam, facilitando a compreensão. Outra vantagem é o desafio cognitivo proposto pelos jogos: é preciso lidar com textos e imagens ao mesmo tempo, interagindo com eles. Terceiro, ao dar ao jogador a chance de escolher o idioma do áudio, tal jogo promoveria um aprendizado ativo, em que o aluno não é apenas um espectador, mas também jogador, ator e personagem de uma história. Além disso, Tereza também dá a entender que seu jogo compreenderia etapas diferentes, organizadas progressivamente: ao acertar as questões de vocabulário - apresentado de uma forma contextualizada - o aluno poderia passar para a próxima etapa, a de ouvir o áudio. De acordo com Gee (apud COPE \& KALANTZIS, 2012), os jogos de computador são ambientes de aprendizado em que o jogador vai construindo um conhecimento intuitivo, fazendo generalizações que lhe serão úteis em outras etapas de seu aprendizado/jogo, cheios de novos desafios. Esse processo, conforme Gee, compreende ciclos de "novo aprendizado", "controle gradual ou por níveis", e "competência progressiva"; a um desafio (com grau de dificuldade proporcional à experiência do jogador), segue-se a chance de familiarizar-se com um novo nível de dificuldade, preparando para um novo desafio. Tereza ainda menciona outro exemplo de como seriam as etapas do jogo que imaginou poder construir a partir de seus esquetes em sala de aula:

Suponhamos que a gente fizesse uma esquetezinha para trabalhar sobre "bullying" de cabelo, aí a gente ia colocar os tipos de cabelos e eles passar por fases, por exemplo, o Nirvana usa cabelo " $x$ ", por exemplo. A gente fazia um joguinho com várias etapas assim, aí você vai acertando e ele fala "agora você pode mudar na esquete isso, isso e isso, que você viu". E é uma coisa que a gente usa, os recursos da comunidade, que são pessoas da 
comunidade que vão participar dessa esquete, então não precisa ser totalmente profissional. Então é bom, a gente se sente valorizado quando a gente participa de alguma coisa para construir a educação que a gente está fazendo, eu acho isso muito interessante.

Bullying, trabalho infantil, cidadania: os temas que Tereza escolheria para compor os esquetes/ jogos mostram sua preocupação em desenvolver uma reflexão crítica por parte de seus alunos, sobre aspectos que fazem parte de sua realidade ${ }^{8}$, de modo que eles possam se posicionar criticamente em relação a eles, e quem sabe ajudar a mudá-los. Tratam-se de temas que interessariam a todos os pesquisadores identificados com letramentos críticos.

A possibilidade de agência - de "apropriar-se" (cri)ativamente das linguagens à nossa disposição para nos expressarmos e posicionarmos enquanto produtores, e não apenas consumidores, de significados - também aparece no depoimento de Tereza, quando ela esclarece que os esquetes a serem usados em suas aulas contarão com a participação de pessoas da comunidade em que a escola está inserida, que poderão se sentir "valorizadas" ao participar da elaboração desses materiais. Ao utilizar esses materiais produzidos localmente, por pessoas de sua comunidade, os alunos tendem a reagir positivamente, sentindo-se valorizados, conforme o depoimento de Tereza:

Eu tô dando a oportunidade da pessoa aprender uma língua, para atuar, para na verdade depois que aquele trabalho que a pessoa colocou ajudando a produzir sirva para ajudar as crianças daquela comunidade a aprender um idioma. E eu não preciso ficar usando necessariamente aqueles desenhos estereotipados dos jogos, que eles são estereotipados [...] e atrapalha muito por que os meninos aprendem a idolatrar pessoas, e os sonhos que ele têm, em vez de eles descobrirem eles mesmos os sonhos que eles
${ }^{8}$ Vale a pena conhecer algumas experiências de utilização de jogos de computador por professores de ensino médio e fundamental no Brasil, narradas em http://educacao.uol.com. br/noticias/2012/08/24/ jogos-eletronicospodem-auxiliar-nosestudos-mas-nao-devemser-muito-didaticos. htm. Entre esses jogos, a reportagem menciona "SimCity", usado para provocar reflexões sobre sustentabilidade e tratamento do lixo, distribuição de energia e planejamento do transporte urbano; "Angry Birds", bastante popular entre professores de física; "Civilization", usado pelos professores de história para ajudar o aluno a entender a evolução dos grupos sociais; e o blog "Games for Change", sobre jogos em inglês com objetivos educacionais explícitos. 
mesmos têm, não, eles vão viver os sonhos do roteirista do joguinho. E que aquele tipo de personagem que ele está representando, porque ele já é estereotipado, é uma moça com o seio muito farto mostrando, é um bumbum muito grande, e geralmente são japoneses, e tipo assim, é como se as japonesas fossem simplesmente objetos sexuais [...] Eu acho isso um desrespeito, e eu não gostaria de colocar esse input para os meninos, porque eu já arrisquei fazer diferente, e os meninos amaram usar outro mecanismo que é realmente esse de valorizar os personagens da comunidade, e os meninos amam. E essa receptividade deles é perfeita, e eles se sentem muito mais valorizados como pessoa por que eles se sentem, "então professora eu posso fazer alguma coisa.

O sentimento de agência - "eu posso fazer alguma coisa" - que Tereza valoriza e procura despertar em seus alunos, através da participação na produção de esquetes para fins didáticos, permite-lhe desenvolver uma atitude crítica em relação aos jogos de computador, baseados nos "sonhos do roteirista" e repletos de personagens dotados de seios e bundas descomunais, característicos de "objetos sexuais". Tereza se deu conta da inadequação dessas imagens à realidade dos alunos e de seu caráter alienante, excludente e desrespeitoso, e resolveu adotar outro "mecanismo" a fim de valorizar os personagens da comunidade local. E conta ter encontrado uma boa receptividade por parte dos alunos, que acabam se sentindo mais valorizados, e dispostos a se tornarem agentes de seu próprio aprendizado. De maneira parecida, Tereza se mostra a favor de trazer temas como bullying e trabalho infantil para a sala de aula, elaborando esquetes e jogos sobre esses temas, de forma a encorajar uma reflexão crítica por parte dos alunos. A moça de seio farto e bumbum grande faz parte da nossa realidade? Qual realidade, ou a realidade de quem? Vocês acham que o jogo foi feito por um homem ou uma mulher? De qual país? Para quem vocês 
acham que foi feito? Vocês já sofreram bullying na escola? O que aconteceu? Como você se sentiria se fosse vítima de bullying? Existe bullying fora da escola também? Por quê? $\mathrm{O}$ que vocês acham de trabalho infantil? Existe na nossa comunidade? Como seriam suas vidas se vocês fossem obrigados a trabalhar? Existem alternativas ao trabalho infantil? Poderíamos arriscar algumas questões que a Tereza poderia formular para problematizar esses temas, e desenvolver um exercício de letramento crítico. O crítico, nesse caso, pode ser entendido de duas formas. Primeiro, como um movimento de apropriação (cri)ativa das linguagens (oral, escrita, mímica, digital, etc.) que temos à disposição para criar os materiais que consideramos mais adequados à nossa realidade de ensino e aprendizado, ao invés daqueles materiais que nos excluem ou nos alienam. Um outro sentido de crítico é sugerido por Menezes de Souza (2011): "ir além do pensamento ingênuo e do senso comum"(2011, p.295); levar o aluno a refletir sobre suas próprias crenças, valores, convicções e maneiras de ler o mundo, e perceber que esses valores, opiniões e crenças - longe de serem "naturais" - se originam na comunidade onde vivemos, nas famílias e nos grupos sociais por onde circulamos:

Aqui, no letramento crítico, precisamos assumir a responsabilidade das nossas leituras e não culpar o autor do texto pela sua escritura; precisamos perceber que o significado de um texto é uma inter-relação entre a escrita e a leitura. Nós estamos nos conscientizando sobre como nós interpretamos o texto. [...] Enfocar aquilo que o aluno acha que é "natural" fazer, levar o aluno a repensar o que é natural para ele e refletir sobre isso. Perceber como aquilo que é natural para ele pode conter preconceitos que podem afetar o outro, gerar preconceito contra pessoas diferentes. E portanto levar o aluno, o aprendiz, a reformular seu saber ingênuo. Então letramento crítico é ir além do senso comum, fazer o aluno refletir sobre 
aquilo que ele pensa que é natural e verdadeiro. Levar o aluno a refletir sobre a história, sobre o contexto de seus saberes, seu senso comum. Levar o aluno a perceber que para alguém que vive em outro contexto a verdade pode ser diferente (MENEZES DE SOUZA, 2011, p.293).

Criticidade, nesse sentido, significa assumir a responsabilidade por nossas leituras, e reconhecermos nosso papel na construção dos saberes e dos sentidos que atribuímos aos textos, nunca "naturais", mas sempre construídos, e relativos a um contexto específico; para Menezes de Souza, é o "ler se lendo" (2011, p.296), isto é, estar atento ao modo como estamos lendo, e como nossas experiências de vida influenciam a forma como lemos, que pode ser diferente do jeito de alguém situado em outro contexto. É o caso do roteirista dos jogos de computador mencionado por Tereza, por exemplo, que tem seus próprios sonhos e visão de mundo. O professor pode ajudar o aluno a perceber que ele tem a opção de "viver os sonhos do roteirista do joguinho", ou não. Joguinhos de computador, assim como videogames, redes sociais e aplicativos de instant messaging, constituem novos letramentos cuja contribuição para o aprendizado - dentro e fora da escola - não pode ser ignorada. Pelo contrário, podem ser discutidos e aproveitados na sala de aula, levando à realização de atividades didáticas baseadas em alguns dos espaços de afinidade de que os alunos fazem parte, como por exemplo, o dos jogos de computador. Com isso, os alunos podem se sentir valorizados enquanto seres humanos e agentes, conforme Tereza sugeriu em seu depoimento.

\section{Considerações finais}

O depoimento de Tereza revela um alto grau de consciência e de comprometimento com o caráter político do fazer pedagógico, o qual, conforme Freeman 
e Johnson (1998) já haviam apontado, é indissociável de uma conjuntura social, cultural e institucional em relação à qual os professores precisam se posicionar criticamente - algo que essa professora parece admiravelmente capaz de fazer, ao rejeitar determinadas práticas e materiais em função de sua inadequação ao contexto social em que está inserida, e procurar estimular a participação de membros da comunidade local nas práticas de ensino e de aprendizagem de inglês em sala de aula. Nesse sentido, a necessidade de reformulação dos conhecimentos trabalhados em formação de professores, defendida por Freeman e Johnson, é retomada por defensores de uma proposta de letramento crítico no ensino de línguas, tal como proposta por Cope e Kalantzis (2012), como já vimos. Essa proposta encontra condições ideais de implementação na sala de aula de Tereza, preocupada em trazer para a escola formas alternativas de letramentos, presentes na música, no teatro e no videogame, e através dessas formas de letramentos a professora cria oportunidades para desenvolver uma reflexão crítica, por parte dela e dos alunos, de como nossos sentidos, valores e identidades sociais são construídos através da linguagem.

A boa notícia é que muitos professores - como a própria Tereza - já reconhecem a importância dos novos letramentos para a educação, e procuram trazê-los para dentro da sala de aula, apesar das dificuldades estruturais (falta de equipamentos, de suporte técnico, ou de espaço adequado, resistência de colegas mais apegados a formas tradicionais de ensino, tempo escasso para a preparação de atividades extras, entre outros). São cada vez mais frequentes os projetos educacionais dedicados a trazer o letramento crítico para a sala de aula, ou propiciar uma aprendizagem através de iniciativas interdisciplinares. É o caso do vídeo de animação "Rockstar e a origem do metal", feito por uma professora do Instituto de Astronomia, Geofísica e Ciências Atmosféricas da 
${ }^{9}$ Para ler mais sobre essas e outras experiências de aprendizagem situada em andamento no Brasil, acesse http:// educacao.uol.com.br/ noticias/2012/08/24/ jogos-eletronicospodem-auxiliar-nosestudos-mas-naodevem-ser-muitodidaticos.htm.
Universidade de São Paulo, para ajudar alunos do ensino médio a entenderem assuntos complexos de química e astronomia. $\mathrm{Ou}$ o projeto desenvolvido em uma escola estadual do município de Paulista (PE), onde os alunos aprendem história, geografia e sociologia enquanto fazem um passeio ciclístico pela cidade, e falam sobre o relevo, os direitos humanos, a invasão holandesa e o cultivo da cana de açúcar. Ou a iniciativa das duas professoras que usam pacotes de gelatina, maçã e abacaxi para ensinarem ciências a crianças de 5 anos de idade. ${ }^{9}$

Iniciativas e projetos educacionais como esses confirmam a necessidade de repensarmos as práticas pedagógicas tradicionalmente ancoradas em um modelo de produção e transmissão de conhecimento. Precisamos, portanto, adotar uma posição crítica em relação a formas de saberes e de conhecimentos que se julgam universais e acima de qualquer interesse particular, e estar cientes da contingência ou da condição de "radical localidade" (LOPES, 2013, p.960) de quem sabe. Ao valorizarmos nossas histórias pessoais e profissionais, interesses e crenças, talvez conseguiremos engajar nossos alunos e professores em atividades significativas e motivadoras, e ajudá-los a se tornarem cidadãos críticos e participativos. No caso da língua inglesa, precisamos criar condições para que eles se apropriem da língua, de modo a utilizarem-na para expressar os sentidos que queiram construir, baseados em suas experiências de vida, anseios, expectativas e necessidades comunicativas. 


\section{Referências}

COPE, B. \& KALANTZIS, M. Literacies. New York:

Cambridge University Press, 2012.

FREEMAN, D. \& JOHNSON, K. E. Reconceptualizing the knowledge-base of language teacher education. TESOL QUARTERLY, Vol. 32, No. 3. Autumn 1998.

GEE, J. P. Situated language and learning. A critique of traditional schooling. New York and London: Routledge, 2004.

JENKINS, J. The Phonology of English as an International Language. Oxford: Oxford University Press, 2000.

LOPES, C. R. Repensando os saberes: mudanças nos paradigmas epistemológicos e a formação de professores de língua estrangeira. Revista Brasileira de Linguística Aplicada. Volume 13. No. 32013.

MENEZES DE SOUZA, L.M.T. O professor de inglês e os letramentos no século XXI: métodos ou ética? In: JORDÃO, C.M., MARTINEZ, J.R. e HALU, R.C. (orgs.) Formação desformatada. Práticas com professores de língua inglesa. Campinas: Pontes, 2011.

STREET, B. Social uses of literacy. Cambridge: Cambridge University Press, 1984.

Recebido em 28/02/2014

Aceito para publicação em 28/07/2014 